Swarthmore College

Works

1992

\title{
The Double-Object Construction, Domain Asymmetries, And Linear Precedence
}

Donna Jo Napoli

Swarthmore College, dnapoli1@swarthmore.edu

Follow this and additional works at: https://works.swarthmore.edu/fac-linguistics

Part of the Linguistics Commons

Let us know how access to these works benefits you

\section{Recommended Citation}

Donna Jo Napoli. (1992). "The Double-Object Construction, Domain Asymmetries, And Linear

Precedence". Linguistics. Volume 30, Issue 5. 837-871. DOI: 10.1515/ling.1992.30.5.837

https://works.swarthmore.edu/fac-linguistics/35

This work is brought to you for free by Swarthmore College Libraries' Works. It has been accepted for inclusion in Linguistics Faculty Works by an authorized administrator of Works. For more information, please contact myworks@swarthmore.edu. 


\section{The double-object construction, domain asymmetries, and linear precedence ${ }^{*}$}

DONNA JO NAPOLI

\section{Abstract}

The behavior of domain-sensitive phenomena in the double-object construction in English has been a topic of controversy. On the basis of this behavior and other facts about the double-object construction Larson (1988) offered an analysis of that construction in which the first object asymmetrically c-commands the second. Jackendoff (1990) responded, arguing both that the domain-phenomena facts do not necessitate the conclusion Larson has drawn and against other points of Larson's analysis. Larson has (1990) replied, reasserting his original analysis. Here I once more discuss domain phenomena in the double-object construction as well as in a handful of other constructions, concluding that linear precedence, not c-command, is the relevant structural relationship for determining domain possibilities in each case. I then offer additional arguments against Larson's analysis of the double-object construction.

\section{A brief history of the issue}

Barss and Lasnik (1986) present evidence to the effect that in the English double-object construction, the second NP is within the domain of the first, but not vice versa:

(1) Ralph gave [the boy] [a lecture about truth].

They outline six grammatical phenomena that display a domainrelationship asymmetry between the two objects. They do not argue that all of these phenomena involve a single notion of domain, nor do they explore in detail the proper definition of domain for any one of these six phenomena.

A variety of other phenomena that exhibit structural asymmetries, however, have been argued elsewhere to involve the particular relationship 
known as binding. If one node can bind another, let us say that the second is within the binding domain of the first. Within the theory of government and binding, binding domains are defined configurationally, where c-command is generally taken to be the relevant syntactic relationship, as follows (Chomsky 1985, 1986). ${ }^{1}$

(2) a. $\mathrm{X}$ c-commands $\mathrm{Y}$ iff the first branching node dominating $\mathrm{X}$ dominates $Y$, and $X$ does not dominate $Y$.

b. $\mathrm{X}$ binds $\mathrm{Y}$ iff $\mathrm{X}$ and $\mathrm{Y}$ are coindexed and $\mathrm{X}$ c-commands $\mathrm{Y}$.

In (3) we see the structures in which $X$ c-commands $Y$, where whether $X$ is the left-daughter or right-daughter of $\mathrm{A}$ is irrelevant:

(3) a.

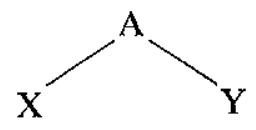

b.

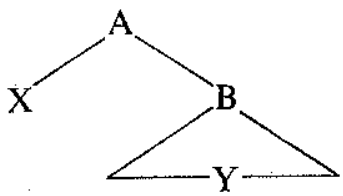

Given that at least binding asymmetries have been attributed to a notion of domain that is based on the relationship of c-command, it is natural to ask whether the domain relationships relevant to the six phenomena discussed by Barss and Lasnik are likewise based on the relationship of c-command. We would then have a definition of domain as in (4):

(4) $\mathrm{Y}$ is in the domain of $\mathrm{X}$ iff $\mathrm{X}$ c-commands $\mathrm{Y}$.

Barss and Lasnik note that if we adopt a definition of domain based on c-command, as in (4), the double-object construction must be analyzed with the first NP asymmetrically c-commanding the second in order to account for the asymmetry in the domain relationship. That is, we must analyze the double-object construction with the first NP in the position of $\mathrm{X}$ and the second NP in the position of $\mathrm{Y}$ in a structure like (3b).

On the other hand, the definition of domain might, instead, be based on the relationship of linear precedence as well as c-command, as in (5a). (5a) is compatible with analyses of the double-object construction in which the first NP asymmetrically c-commands the second, along the lines of (3b); as well as with analyses in which both NPs c-command each other, as shown in $(5 \mathrm{~b})$ :

(5) a. $\mathrm{Y}$ is in the domain of $\mathrm{X}$ iff $\mathrm{X}$ c-commands $\mathrm{Y}$ and $\mathrm{X}$ precedes $\mathrm{Y}$.

b.

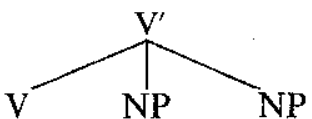

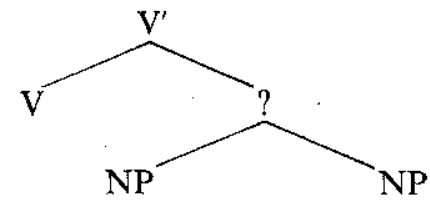

The ternary-branching analysis of the double-object construction in (5b) can be considered the traditional analysis. The other analysis in (5b) is supported in Kayne (1984).

Larson (1988), who is a strong proponent of the idea that any node can have at most two daughters (the binary-branching hypothesis), argues for the first alternative. Jackendoff (1990) responds to Larson, arguing that linear order must be included among the possible conditions for establishing domains in general, therefore the asymmetries noted by Barss and Lasnik need not be taken as evidence for asymmetric c-command between the two NPs in the double-object construction. He offers, additionally, several problems with Larson's particular analysis of the doubleobject construction.

Many of these problems are taken up in Larson (1990), where Larson argues that the evidence presented by Jackendoff can, in fact, be handled adequately both with a c-command-based definition of domain and with a linear-precedence-based definition of domain, thus leaving us with no clear evidence to choose between the two. The only exceptions to this are in discussions about VP ellipsis and gapping constructions, where Larson argues that only a c-command-based definition of domain is adequate. I return to a discussion of particular aspects of Larson's analysis in section 7.

Here we will look at the six phenomena in Barss and Lasnik. We will see that not only is linear order a factor in determining domain for these six phenomena within the double-object construction, as Jackendoff has argued, but it is the only structural factor relevant to determining domain in certain structural contexts (as developed in section 4 below), of which the double-object construction is one example. In addition, new problems with Larson's analysis of the double-object construction will be brought out, leading us to the conclusion that analyses such as those in (5b) are more viable than Larson's with respect to the evidence here.

\section{Six grammatical phenomena exhibiting domain asymmetries}

The six phenomena that Barss and Lasnik outline are exemplified in (7)-(12) below with sentences that have the double-object construction. Jackendoff shows that the same domain-relationship asymmetry exists in other constructions, using the four in $(6 \mathrm{a})-(6 \mathrm{~d})$ :

(6) a. nonalternating double objects (as in I denied [John] [the money].) 
b. alternating NP-PP complements (as in I blamed [the mistake] [on John].

I blamed [John] [for the mistake].)

c. double PP complements with free order (as in I talked [to John] [about Bill].

I talked [about Bill] [to John].)

d. double PP complements in nominals (as in a gift [from Bill] [to Sue]

a gift [to Sue] [from Bill])

In (7)-(12) below, the (a) examples are from Barss and Lasnik or are variations on examples from Barss and Lasnik (where my changes serve only to keep the contrasting example pairs parallel) and the (b) examples are constructed along the lines of Jackendoff. The reader can refer to Jackendoff for examples of all four constructions (when they exist) for each phenomenon. In instances where two PP complements of a V or $\mathrm{N}$ can come in either order, I have demonstrated with only one of the orders. Both orders, however, are demonstrated in Jackendoff's article. ${ }^{2}$

The six phenomena are demonstrated here:

(7) Reflexive anaphors:

a. double-object construction

I showed [John/him $]_{i}[\text { himself }]_{i}$ (in the mirror).

*I showed [himself $]_{i}[\mathrm{John}]_{\mathrm{i}}$ (in the mirror).

b. double PP complements in nominals

gifts from [John and Bill $]_{\mathrm{i}}$ to [themselves $]_{\mathrm{i}}$

* gifts from [themselves $]_{\mathrm{i}}$ to $[\text { John and Bill }]_{i}$

(8) Quantified-NP-bound pronouns:

a. double-object construction

I showed [every lion $]_{\mathrm{i}}\left[[\text { its }]_{\mathrm{i}}\right.$ trainer].

*I showed [[its] trainer] [every lion] $]_{i}$.

b. double PP complements

I talked to [every girl $]_{\mathrm{i}}$ about $\left[[\text { her }]_{\mathrm{i}}\right.$ mother $]$.

?*I talked to $\left[[\text { her }]_{\mathrm{i}} \text { mother] about [every girl }\right]_{\mathrm{i}}$.

(9) WH movement and weak crossover: ${ }^{3}$

a. double-object construction

[Which trainer $]_{j}$ did you show $[\mathrm{t}]_{\mathrm{i}}\left[[\text { his }]_{\mathrm{i}}\right.$ lion]?

*[Which lion $]_{\mathrm{i}}$ did you show $\left[[\mathrm{its}]_{\mathrm{i}}\right.$ trainer $[\mathrm{t}]_{\mathrm{i}}$ ?

b. double PP complements

$[\text { Which daughter }]_{i}$ did you talk to []$_{i}$ about $\left[[\text { her }]_{i}\right.$ mom]?

?*[Which mom $]_{i}$ did you talk to $\left[[\text { herr }]_{i}\right.$ daughter $]$ about $[t]_{i}$ ?

(In [9] above and [10] below, I have indicated the trace left by movement, although the sources for these examples did not.)
(10) Superiority: ${ }^{4}$

a. double-object construction

$[\text { Who }]_{i}$ did you give $[\mathrm{t}]_{\mathrm{i}}[$ which book]?

*[Which book $]_{i}$ did you give [who] [t $]_{i}$ ? (OK only with an echo reading).

b. double PP complements

[Which girl] did you talk about [t $]_{\mathrm{i}}$ to [which boy]?

?*[Which boy $]_{\mathrm{i}}$ did you talk about $[$ which girl $]$ to $[\mathrm{t}]_{\mathrm{i}}$ ?

(11) Each ... the other:

a. double-object construction:

I gave [each lion $]_{\mathrm{i}}\left[[\text { the other's }]_{\mathrm{i}}\right.$ trainer $]$.

${ }^{*}$ I gave [[the other's $]_{\mathrm{i}}$ trainer] [each lion $]_{\mathrm{i}}$.

b. double PP complements in nominals

the gift from [each boy $]_{i}$ to [the other $]_{i}$

* the gift from $[\text { the other }]_{i}$ to $[\text { each boy }]_{i}$

(12) Polarity any: $:^{5}$

a. double-object construction:

I gave [no one] [anything].

*I gave [anyone] [nothing].

b. double PP complements in nominals

gifts from [few of the boys] to [any of the girls]

* gifts from [any of the boys] to [few of the girls]

\section{Linear precedence as a factor in defining domain}

While the most immediate conclusion consistent with the data in section 2 is that linearity is relevant to the determination of domain for these six phenomena, a proponent of a definition of domain based on c-command might pursue the possibility that the first NP in all the examples in section 2 asymmetrically c-commands the second. For the (a) examples that would amount to claiming that the proper analysis of the doubleobject construction is that in (3b) (where the first object is $X$ and the second object is $\mathrm{Y}$ ). We will examine a particular instantiation of this analysis in section 7. For the (b) examples, there are at least two alternative accounts one could propose.

\subsection{Some Ps count, others don't}

First, one could argue that the $\mathbf{P}$ introducing the first relevant NP does not count in the computation of c-command possibilities. This is true for some languages (such as Modern Irish; see Chung and McCloskey 1987: 215 , note 26). However, it is precisely the effect of the PP node that has 
been traditionally called upon to establish the role of the notion of c-command in discussions of binding using English data. Thus this response is unmotivated for English. Anyone taking this approach needs to argue strongly for a distinction in types of Ps.

And, certainly, an obvious distinction can be made: some Ps introduce arguments of a V and other Ps do not. One could propose that the first type of $\mathrm{P}$ can be overlooked in computing c-command possibilities. But this approach only begs the question. Why should the syntactic relationship of c-command be sensitive to the thematic structure of a sentence?

\subsection{Some Ps reanalyze, others don't}

Alternatively, one might argue (as Burzio 1986 does) that the $\mathrm{P}$ has been incorporated into the preceding verb or noun to form a new $\mathrm{V}$ node (or $\mathrm{N}$ node, in the case of double PP complements in nominals) dominating both words, as in Hornstein and Weinberg (1981). After reanalysis the first NP is no longer inside a PP but is instead dominated by the $\mathrm{V}^{\prime}$ (or $\mathrm{N}^{\prime}$ ) node, and thus c-commands the second NP, as in (13):

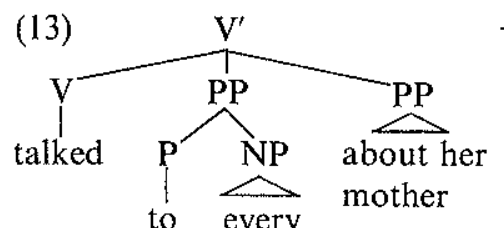

girl
While there are extensive treatments of reanalysis in the literature (as in Kajita 1977 and Baker 1988), we must be particularly careful in appealing to this type of mechanism when it comes to issues of ccommand. As Bach and Partee (1980) warn, if reanalysis is not called for on independent grounds, the appeal to reanalysis robs principles that make use of the notion of c-command of any predictive power. Furthermore, we are once more faced with the question of how the grammar distinguishes between those Ps that can be reanalyzed and those that cannot.

In fact, in the case of the double PP complements of $\mathrm{V}$ and $\mathrm{N}$, evidence against reanalysis exists. In (14) we find that a modifier of the head $V$ or $\mathrm{N}$ can intervene between the head $\mathrm{V}$ or $\mathrm{N}$ and a following $\mathrm{P}$, and still the binding asymmetries are observed.

(14) I talked quietly to $[\mathrm{Jim}]_{\mathrm{i}}$ about [himself $]_{\mathrm{i}}$.

*I talked quietly to [himself $]_{\mathrm{i}}$ about $[\mathrm{Jim}]_{\mathrm{i}}$. gifts long overdue from [John and Bill] $]_{\mathrm{i}}$ to [themselves] ${ }^{*}$ gifts long overdue from [themselves $]_{i}$ to [John and Bill]
The presence of such a modifier would require us to allow the operation of reanalysis to form a new $\mathrm{V}$ out of a verb, an adverb or adjective phrase, and a preposition - a dubious move, at best. ${ }^{6}$ And, if passivization is a diagnostic for reanalysis, then the failure of (15) shows reanalysis has not applied: ${ }^{7}$

(15) *Jim was talked quietly to.

(compare Jim was talked to [for hours and hours].)

Other examples similar to (14) can be constructed with enough ingenuity in concocting situations:

(16) As a responsible psychiatrist, I found that I had to side firmly with $[\text { Tim }]_{i}$ against [himself $]_{i}$.

*As a responsible psychiatrist, I found that I had to side firmly with $[\text { himself }]_{i}$ against $[\text { Tim }]_{i}$.

Furthermore, when two PPs follow an NP, where all three nodes are arguments or adjuncts of a V, the familiar asymmetry is found. ${ }^{8}$ Two possible structures for the VP in the examples in (17) before any sort of reanalysis are offered after the examples:

(17) I gave snapshots to $\mathrm{John}_{\mathrm{i}}$ for himself $\mathrm{f}_{\mathrm{j}}$ and his sister.

*I gave snapshots to himself for $\mathrm{John}_{\mathrm{i}}$ and his sister.

I gave snapshots to every boy $y_{i}$ for his ${ }_{i}$ mother.

*I gave snapshots to his ${ }_{i}$ mother for every boy ${ }_{i}$.

Which boy $y_{i}$ did you give snapshots to $t_{i}$ for his $s_{i}$ mother?

*Which mother $r_{i}$ did you give snapshots to her $r_{i}$ son for $t_{i}$ ?

Which boy ${ }_{i}$ did you give snapshots to $t_{i}$ for which girl?

*Which girl $_{\mathrm{i}}$ did you give snapshots to which boy for $\mathrm{t}_{\mathrm{i}}$ ?

I gave snapshots to each boy ${ }_{i}$ for the other's $s_{i}$ mother.

*I gave snapshots to the other's $s_{i}$ son for each mother ${ }_{i}$.

I gave snapshots to no boys for any mothers.

* I gave snapshots to any boys for no mothers.

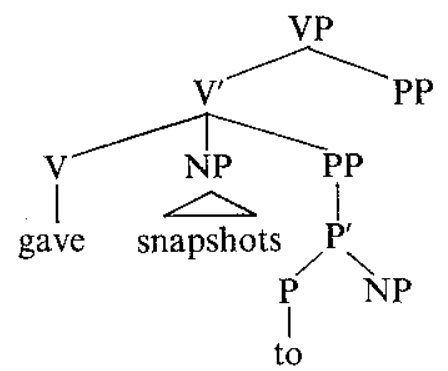

or

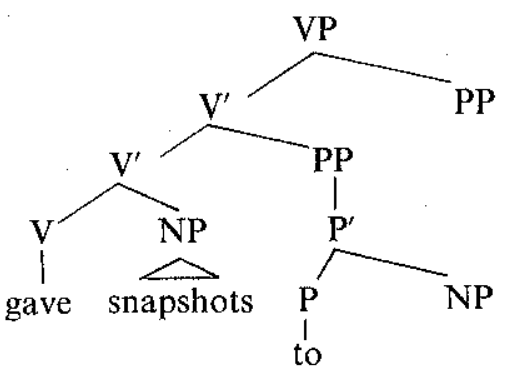


Here the string gave snapshots to would have to be reanalyzed as a single $V$. That is, we would now have to allow the operation of reanalysis to form a new $\mathrm{V}$ out of a verb, an NP, and a $\mathrm{P}$. Our reanalysis operation is becoming more and more suspect. ${ }^{9}$

Finally, there are several types of examples in which one simply would not want to appeal to reanalysis to account for the ability of an NP inside a PP to have domain over some NP outside the PP, for reasons I will discuss following their demonstration. Consider the following: ${ }^{10}$

(18) I always eat dinner \{with/after\} each worker ${ }_{i}$ on his $s_{i}$ birthday.

(19) Who did you eat dinner $\{$ with/after $\} t_{i}$ on his birthday?

(20) I ate dinner \{with/after\} each of the two workers $s_{i}$ on the other's $s_{i}$ birthday.

At LF these sentences have the structures here (and see note 3):

(21) each worker $r_{i}$ [I always eat dinner \{with/after $t_{i}$ on his $s_{i}$ birthday]

(22) who $_{i}$ [did you eat dinner $\left\{\right.$ with/after $t_{i}$ on his $s_{i}$ birthday]

(23) each of the two workers $s_{i}\left[I\right.$ ate dinner $\{$ with/after $\} t_{i}$ on the other's $s_{i}$ birthday]

Here the trace must be bound by the operator. Given the bijection principle (which requires that any operator binds precisely one variable and every variable is bound by a single operator, as discussed in note 3), the possessives cannot also be bound by the operator. Therefore, the trace in each example must be taken to bind the possessive. These traces precede the possessives, but they do not c-command them. Thus such examples offer strong evidence that linear precedence rather than ccommand is the relevant structural relationship for determining domain (here, binding domain).

One would not appeal to restructuring in (21)-(23) for two reasons. The first reason is already exemplified above in (17): an object of the V intervenes between the $\mathrm{V}$ and the $\mathrm{P}$. But even if one adopted an operation of reanalysis that could operate on V-NP-P strings, there is a second reason for not appealing to restructuring in (21)-(23) based on the thematic structure of the sentence. The whole effect of restructuring with the object of a $\mathrm{P}$ becoming a sister to a newly reanalyzed $\mathrm{V}$ is to promote an argument of a $\mathrm{V}$ into sister position to that $\mathrm{V}$. There appears to be no motivation in English to appeal to this particular restructuring operation with respect to Ps that introduce an NP that is not an argument of the V. And in (18)-(23), the object of with or after is not an argument of the $\mathrm{V}$.

Let us go through support of this last claim by examining after phrases, although we could as easily have examined with phrases. That is, the following discussion is representative of the sorts of data and issues that come to bear on the question with a wide range of Ps. For that reason, the discussion, although somewhat tangential to the major points of this paper, will be detailed.

Evidence that the object of after in sentences like (18)-(23) does not receive a theta role is easy to find. First, there is no obvious candidate for which a particular theta role could cover all the possible objects of after in the sense of 'temporally subsequent to':

(24) I ate dinner after Bill.

I ate dinner after the news.

I ate dinner after dessert.

I ate dinner after my bath.

We are not talking here about a choice between two clearly discernible theta roles. Instead, the object of after in such examples bears no semantic relationship to the rest of the sentence beyond giving us some temporal point that preceded some other temporal point in the rest of the sentence. It is precisely this sort of extreme vagueness or underdetermination of semantic role that leads one to claim that an NP does not receive a theta role. (Compare, for example, the semantic underdetermination of a possessive NP with most concrete head Ns that led Williams [1982] to argue that possessive NPs in such a context do not bear a theta role.)

Furthermore, the object of after here cannot serve as the subject for a secondary predicate nor the antecedent for a reflexive:

(25) *I ate after Bill as my date.

(compare I conferred with Father Catania as my trusted confidant.)

*I ate after Bill (all) by himself.

(compare I ate after Bill (all) by myself.

I saw Bill (all) by himself in the grocery yesterday.)

In contrast, there is another use of after in which it is a predicate rather than a $\mathbf{P}$ that introduces an adjunct. In this use the object of after does receive a theta role, and its object can serve as the subject for a secondary predicate and as the antecedent for a reflexive:

(26) She's always after any new community residents as potential members of the school board.

I'm after Jim for himself, not for his money.

(And see Napoli [1989] for additional evidence.)

We would therefore not appeal to restructuring to account for (18)-(23). Thus (18)-(23) require that we adopt a definition of domain based on linear precedence. 
As we expect; if we reverse the order of the complements in (18)-(20), the binding fails.

(27) *I always eat dinner on his $\mathrm{s}_{\mathrm{i}}$ birthday $\{$ with/after $\}$ each worker $\mathrm{r}_{\mathrm{i}}$ *Who $o_{i}$ did you eat dinner on his, birthday $\{$ with/after $\}$ ?

*I ate dinner on the other's $s_{i}$ birthday $\{$ with/after $\}$ each of the two workers $_{\mathrm{i}}$.

Here the structures at LF are as follows:

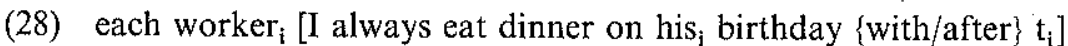
who $_{i}$ [did you eat dinner on his $s_{i}$ birthday \{with/after $t_{i}$ ] each of the two workers $s_{i}$ [I ate dinner on the other's birthday $\left\{\right.$ with/after $\mathrm{t}_{\mathrm{i}}$ \}

Again the operator binds the trace. But here the trace is unable to bind the preceding possessive, hence (28) is a violation of the bijection principle.

\subsection{Section conclusion}

I conclude that Jackendoff was correct in attributing the effects in his examples in section 2 above to linearity. The conclusion was arrived at without making any theory-general or data-specific assumptions about binary- versus ternary-branching possibilities. We must admit that linearity is relevant to determining domains, regardless of one's stance on branching restrictions.

\section{Linearity as the sole factor in domain relationships between citizens of the same phrase}

While we can conclude that linearity is relevant to determining domain in the phenomena exemplified in section 2 , I would like to make a stronger claim. If we look back over all the examples thus far, the first relevant NP, by definition, precedes the second. However, in many cases the first relevant NP does not c-command the second, as we have seen. This fact would follow if the relationship of c-command were, in fact, irrelevant to domain relationships in general. Unfortunately, that cannot be the case.

There is a formidable amount of literature on the issue of what factors are relevant to establishing domains, particularly binding domains. Most of this literature within GB has concluded that c-command is the only relevant structural relationship (Reinhart 1976, 1979 for anaphora;
Hornstein 1984; May 1985; Reinhart 1987 for QNP-pronoun relations). Earlier work (such as Langacker 1966 for coreference; Jackendoff 1972 for QNP-pronoun relations), however, argued that linear precedence was a relevant factor, in addition to a domination relationship, and, more recently, Ruszkiewicz (1984) has argued for this combination for binding of reflexives in English, while Lee (1991) has shown that at least linearity must be a factor in determining scope of quantifiers in Chinese, and Cowart (1990) has argued that linearity is a factor in anaphor binding in coordinate NPs. In the present work we have seen evidence not only that linear precedence is relevant to the determination of domains, but that the domination relationship of c-command is irrelevant in some instances (as in [14]-[27]). I believe these three different positions, however, may be reconciled.

In all the examples used to demonstrate the relevance of linearity and the irrelevance of c-command to the determination of domains in the preceding sections, the two nodes under discussion are contained inside a single VP in a simple sentence. In contrast, the crucial evidence put forth in Reinhart (1976), for example, for claiming that c-command is the only factor relevant to binding domain involves instances in which the binder and the bindee are often members of different clauses. Reinhart herself leaves open "the question whether inside the VP, linear order may play (exceptionally) a role in determining anaphora option" (1976: 158). I would press for a stronger conclusion. Consider the notion of citizen, defined here: ${ }^{11}$

(29) All arguments and adjuncts of a theta-assigning head $X$ are citizens of XP.

Note 1: An object of a $\mathrm{P}$ where the $\mathrm{PP}$ is an argument or an adjunct of a head $\mathrm{X}$ is a citizen of $\mathrm{XP}$.

Note 2: A subject, as an argument of a theta-assigning head $\mathrm{X}$, is a citizen of XP whether the subject is internal or external to XP.

The notes on (29) are crucial. Note 1 explicitly denies that objects of $P$ should have any fewer possibilities in domain relationships than other NPs (with the familiar caveat, of course, that for reflexive binding, argumenthood is relevant). It is this note that allows the definition of domain in (30) to be distinguished from a definition involving both linear precedence and c-command. Note 2 makes it clear that the important factor for citizenship is predicate-argument structure, not syntactic position.

Let us call all citizens of the same phrase paesani. We can dub (30) the linear-precedence principle (LPP): 
(30) Linear precedence principle: If $X$ and $Y$ are paesani, then $X$ is within the domain of $\mathrm{Y}$ iff $\mathrm{Y}$ precedes $\mathrm{X}$.

In order to judge whether the LLP adequately accounts for the data, we might ask first whether it is based on too exclusive a definition of citizen and, next, whether it is based on too inclusive a definition of citizen.

\subsection{Too exclusive?}

In most of the examples we have discussed so far, the relevant NPs were paesani. However, in some examples one of the NPs was a possessive and the other NP was outside the NP that contained the possessive. According to the definition in (29), the two relevant NPs; then, were not paesani (as is the case in [8], [9], [11a], several examples in [17], [18], [19], [20], and [27]). That NPs with this structural relationship are correctly excluded by (29) can easily be shown by looking at examples with yet another construction not yet examined: that in which we have a DO followed by a prepositional IO. ${ }^{12}$

(31) *I gave [Mary's pictures] to [herself $]_{\mathrm{i}}$.

*I showed [every girl's $s_{i}$ pictures] to [her $]_{i}$.

*I offered [each girl's $s_{i}$ sister] to [the other's $s_{i}$ brother].

The bracketed NPs in (31) are paesani. But the coindexed NPs (where in every case the first NP is a possessive and the second NP falls outside the NP that contains the possessive) are neither arguments nor adjuncts to the same theta-assigning head. Thus the coindexed NPs are not paesani and the second is therefore not within the domain of the first.

If we stick to the definition in (29), a possessive and an NP outside the minimal NP that contains the possessive are never paesani and the LLP will have nothing to say about binding possibilities between the possessive and the other NP. Looking back at section 2, we can see that the LLP will now be pertinent to four of the grammatical phenomena exemplified there: reflexive anaphors (in [7]), superiority (in [10]), each ... the other (in [1 1]), and polarity any (in [12]). It will not, however, help us to account for data on quantified-NP-bound pronouns (in [8]), or on weak crossover (in [9]) - which is essentially the same phenomenon (see note 3 ). That is because examples like those in (8)-(9) always involve a possessive, thus the two relevant nodes are never paesani.

Yet we have already seen that linear precedence is the important factor for binding in these phenomena. Likewise, those phenomena that can involve paesani but just happen not to in a given example because one of the relevant nodes is a possessive also show linearity effects. For example, consider the VP-versus-NP examples in (11) above, and compare (32) to (12):

(32) I gave [no one's brother] [anything]

*I gave [anyone's brother] [nothing].

These facts suggest that the definition of paesano is, after all, too exclusive. Still, in light of (31) we know we cannot allow all possessives to be honorary citizens of the same phrase the minimal NP that contains them is a citizen of. Furthermore, we cannot say only a possessive that is a binder can be given honorary citizenship because of (31), nor can we say only a possessive that is a bindee can be given honorary citizenship because of (32).

I regret that I cannot find a way to revise the LLP so that it will be inclusive enough to account for the relevant examples. Still, two points should be stressed. One is that linearity is the crucial factor for all the phenomena in section 2 when the binder and bindee are in some sense local to one another, whether or not I am capable of formalizing the sense of locality at work here. Second, one major goal of the present work is to offer arguments against that analysis of the double-object construction discussed in section 7. And the LLP as presently stated is adequate for the task of accounting for the data on the double-object construction in section 2. Thus I will now press forward, recognizing that the definition in (29) is too exclusive and eventually needs to be revised.

\subsection{Too inclusive?}

By defining all arguments of a head $X$ as citizens of the XP regardless of where they fall syntactically, I am including the subject of a clause as a potential $\mathrm{X}$ or $\mathrm{Y}$ in (30), as Note 2 in (30) makes explicit. ${ }^{13}$ Given the phrase structure of English, an item in subject position normally not only linearly precedes all other citizens of the phrase it is a citizen of (that is, of the VP) but c-commands them, as well. Therefore, for most of the six phenomena in section 1 it is not possible to present examples that clearly demonstrate the relevance of linearity to domain relationships in which the subject is involved. However, there is one phenomenon, the polarity any phenomenon, for which we can test whether or not linearity is relevant with regard to subjects, and Ladusaw (1979) has already, in fact, done this.

Ladusaw argues that linear order at $\mathrm{S}$ structure is relevant to establishing the domain for the licensing of polarity any by a negative both inside 
and outside the VP. He points out that the negative in (33a) can have wide scope. Therefore, if linear precedence at $\mathrm{S}$ structure were not relevant to establishing the domain for licensing here, we would expect that any could occur in subject position where the negative inside the VP had wide scope. But this expectation fails.

(33) a. Every student wasn't there.

b. *Any dog didn't bark.

We have one solid case, then, from which I would argue that the definition of citizen in (29) is not overly inclusive.

This is just one case and it is a case in which the relevant structural relationships are determined at $\mathrm{S}$ structure rather than $\mathrm{LF}$ (in contrast to binding, for example). Furthermore, as we saw in note 12 , polarity any constructions have certain peculiarities with respect to domain that are not shared by the other domain-sensitive phenomena exemplified in section 2. Thus it could well be that the definition in (29) is too inclusive and should be restated so that citizens of XP must be located within XP at the point at which domain is established (generally, at LF) ${ }^{14}$ However, in the absence of any telling evidence to the contrary, I will assume that the definition in (29) is adequate. And since I know of no irrefutable evidence that c-command is relevant to domain relationships involving paesani (whether or not one of the paesani is a subject), I stand by (29) and $(30){ }^{15}$

\subsection{The LLP versus a reformulation of condition $A$}

Notice that the LLP pertains to domain relations between nodes that are local to one another. However, the situations in which nodes are paesani form a proper subset of the situations in which nodes are local to one another in the notion of locality normally assumed in condition $\mathrm{A}$ of the binding theory.

Condition A requires all anaphors to be locally bound. The definition of locality with respect to condition $\mathrm{A}$ has been the topic of much debate. The classical definition would have two nodes be local to one another if they have the same governing category, where a governing category for a given node $\mathrm{A}$ is the minimal NP or IP that contains $\mathrm{A}$, the governor of $\mathrm{A}$, and a subject accessible to A. ${ }^{16}$

We might then ask whether the more restrictive sense of local, the sense found when two nodes are paesani, could suffice for condition $\mathrm{A}$. That is, we might ask whether a reformulation of condition $\mathrm{A}$ of the binding theory to the effect that anaphors must be A-bound by a paesano would be empirically adequate to account for the effects attributed to condition A (and see note 16). This modified condition A could account for the fact that a possessive cannot serve as the antecedent for an anaphor that falls outside the minimal NP that contains it, whether the possessive bears a theta role or not, as in (34):

(34) a. *[The baby's $s_{j}$ mother] babbled to himself $f_{i}$.

b. *[The Huns' brutal destruction (of the city)] surprised even themselves . $_{\text {. }}$

That is because any possessive that is a potential antecedent for a reflexive (that is, a possessive that receives a theta role) is a citizen of the minimal NP that contains it (the bracketed NP in [34]), thus it cannot be a paesano to an anaphor that falls outside the minimal NP that contains it. In (34a) the possessive does not bear a theta role, so it is not a potential antecedent for the anaphor in any case. In (34b) the possessive bears a theta role, but it is a citizen of the bracketed NP, of which the anaphor is not a citizen. $^{17}$

However, other questions for this reformulation of condition $\mathrm{A}$ now arise. Consider the fact that sentences like (35) are grammatical:

(35) John $\mathrm{n}_{i}$ likes [that picture of himself ${ }_{i}$ ].

Here, if we were to maintain the modified condition $A$, we would have to note that the anaphor is behaving as though it is a citizen of the VP rather than of the bracketed NP. Yet we know that "picture" nouns can take citizens of their own, accounting for familiar contrasts, such as (36):

(36) a. John likes [Mary's $s_{i}$ picture of herself $f_{i}$ ].

b. *John $n_{\mathbf{i}}$ likes [Mary's picture of himself $f_{\mathbf{i}}$ ].

([36a] contrasts with the earlier examples in [31], since the anaphor and its antecedent are inside the same NP in [36a] but not in [31].) We might try to claim first that while "picture" nouns can evoke an event and thus set up an argument structure, they need not if they do not have a possessive. Thus the bracketed NPs in (36) would have their own citizens, but the bracketed NP in (35) would not. Then we could claim further that the object of picture in a sentence like (35) is semantically promoted somehow, so that it can become a citizen of the VP. The resulting analysis of (35) is somewhat acrobatic and can be taken as evidence that, unfortunately, the notion of locality that condition $\mathrm{A}$ is based upon (however that notion should be stated) is more inclusive than that found in the LLP.

Please note that sentences such as (35) do not offer empirical evidence against the LLP. Rather, the LLP claims that if two nodes are paesani, 
domain of one over the other is established by linear precedence only. The LLP does not make any claims about how domain is established if two nodes are not paesani. Whether or not linearity and/or c-command are relevant factors to determining domain for phenomena in which the relevant nodes are not paesani is a separate matter that is not addressed in this paper (although I noted at the end of section 4.1 the desirability of expanding the definition of paesano so that the LLP could account for all the data in section 2).

\subsection{Locality for the LLP versus locality for a $C F C$}

Let us now consider another alternative. Every argument and piece of data we have discussed up to this point would suggest that a principle of linear precedence should be incorporated into our notion of domain when we are dealing with nodes that are somehow local to each other. And everything we have discussed thus far would suggest that (30) (using the definition in [29]) is as close to an adequate way of doing this as I have yet been able to devise. Still, we should make sure that no other independently needed notion of locality is up to the task before we admit the new notions of citizen and paesano.

An obvious tack is to try to see if the notion of complete functional complex will help us here. A CFC is a maximal projection within which "all grammatical functions compatible with its head are realized" (Chomsky 1985: 169; see Giorgi 1987; Grimshaw 1988). On this definition, a $\mathrm{CFC}$ requires a structural subject. We might ask whether we could rephrase the LLP to say that if $X$ and $Y$ are members of the same minimal $\mathrm{CFC}, \mathrm{X}$ has domain over $\mathrm{Y}$ iff $\mathrm{X}$ precedes $\mathrm{Y}$. Unfortunately, this formulation of the LLP is not empirically adequate. Consider (37):

(37) *The description of $J_{o h n} n_{i}$ flatters himself $f_{i}$.

*The description of every boy $y_{i}$ flatters him $_{i}$.

*The description of each boy $y_{i}$ flatters the other ${ }_{i}$.

*The description of no boy flatters anyone.

All of the sentences in (37) consist of a single CFC, yet linearity is not sufficient to allow the second relevant node to be within the domain of the first relevant node. (Notice that the relevant nodes in [37] are not paesani.)

I have found no existing notion in the literature that is empirically adequate for reformulating the LLP. The locality involved here is cohesive in a narrower sense than the locality involved within a CFC. It seems we must admit the notions of citizen and paesano into the grammar.

\section{Other languages}

The LLP seems to be needed in order to account for the English data we have seen in this paper. We would therefore hope that other languages make use of it as well. Certainly, some others do (including Italian), although not all do.

\subsection{Italian}

Consider (38), from Giorgi (1984):

(38) Gianni ha rincondotto Maria $_{\mathbf{i}}$ a se stessa $a_{i}$ con una lunga terapia psiconanalitica.

"Gianni brought Maria back to herself with a long psychoanalytical therapy.'

Here the DO binds an anaphor in IO position. Thus anaphors in Italian can be bound by nonsubjects. We can find speakers who accept sentences in which an IO (which in Italian is an object of a P) binds an anaphor that is the object of another $\mathbf{P}$, as in (39a) ${ }^{18}$ Significantly, all speakers find (39b) totally ungrammatical:

(39) a. Ho parlato a Maria ${ }_{i}$ di se (stessa).

'I spoke with Maria about herself.'

b. *Ho parlato a se (stessa) ${ }_{i}$ di Maria ${ }_{i}$.

'I spoke to herself about Maria.'

Since Italian shows no evidence of having a rule that reanalyzes Ps into the $\mathrm{V}$, the contrast between (39a) and (39b) is accounted for with the LLP, but not with a notion of binding based on c-command (but see discussion below).

Italian unmarked word order places the IO before any other OPs. If we reverse that word order in our examples, we find the following results. Speakers who fully accept (39a) find (40) marginal at worst:

(40) ?Ho parlato di se (stessa) a Maria ${ }_{\mathrm{i}}$.

'I spoke of herself to Maria.'

I follow Burzio (1986: 66) and Giorgi and Longobardi (1991: 27) in attributing the effects in (40) to a stylistic rule that operates at a level that does not affect binding. Thus the LLP, which would look at the structure of (40) before the stylistic rule applied (that is, at the structure in [39a]), can handle the data.

Unfortunately, these are not the only relevant data on Italian. Giorgi 
and Longobardi (1991) look at binding possibilities within NPs. They note that both (4la) and (41b) are grammatical:

(41) a. la finta lettera di Gianni a se stesso; 'the false letter by Gianni to himself'

b. la finta letter a se stesso; di Gianni 'the false letter to himself by Gianni'

They go on to argue that ( $41 \mathrm{~b}$ ) gives the order of constituents before the operation of the stylistic rule that shifts complement order. They argue further that in (41) the P di does not count for purposes of determining c-command since it is equivalent to a case marker. In their analysis Gianni asymmetrically c-commands the anaphor in $(41 \mathrm{~b})$ because Gianni is attached higher in the tree than the anaphor. All along, they assume that linear precedence is irrelevant to binding and that c-command is the crucial structural relationship.

Presumably Giorgi and Longobardi would account for (39a) above by claiming that the $\mathrm{P} a$, like agentive $d i$, does not count for the purposes of computing c-command possibilities.

A serious refutation of Giorgi and Longobardi would deal with issues of NP syntax and the structure of Italian that go beyond the scope of the present paper. Instead, let us focus only on their most crucial claim that certain Ps don't count in the computation of c-command possibilities, but others do. Those Ps are the case markers.

Two objections can be raised. First, how do we know which Ps count as case markers and which do not? We cannot use the possibility of replacement by a clitic as a test, since an agentive di NP has no corresponding clitic. I see no clear syntactic criterion for making the determination. Instead, I suspect that the most nearly accurate stab at a definition would be to say that Ps that introduce an argument of some theta assigner other than the P itself are case markers. But, unfortunately, with that definition the $d i$ of (39a) is also a case marker, so, according to Giorgi and Longobardi, its object should be able to bind a preceding anaphor, but it absolutely cannot, as we saw in (39b).

The second objection is related to the first: why should the syntactic notion of c-command be sensitive to the difference between Ps that are essentially case markers and Ps that aren't, if that difference is not a syntactic difference?

Instead, all the data on Italian are accounted for with the LLP, so long as (4la) exemplifies the underlying word order of complements inside NPs, rather than (41b). No appeal to (obscure) differences in classes of $P s$ is needed with this account.

\subsection{OS languages}

Others have pointed out to me that the LLP cannot be a universal since in languages in which the DO characteristically precedes the subject, if the object and subject are coindexed, only the object can be an anaphor. So far as I know, this description of the data is accurate. I have considered data on three such languages presented in Pullum (1980) and in some of his sources (Kennan 1976 for Malagasy; Derbyshire 1977, 1979a, 1979b for Hixkaryana; and Colarusso 1976 for Bzhedukh). I have also considered data on Tzotzil offered to me by Judith Aissen (personal communication, 1992). In all but Malagasy, an object that is an anaphor is incorporated into the $\mathrm{V}$ (in a Baker-style operation perhaps, or as an affix, as Pullum says).

While anaphors that are incorporated into the $\mathrm{V}$ raise many issues for analysis that might allow me to view Hixkaryana, Bzhedukh, and Tzotzil as compatible with the LLP, Malagasy seems to be an undebatable instance of a language that does not make use of the LLP. I must therefore admit that the LLP is a language-specific principle. It may be that whether a language makes use of linear precedence or c-command or both to establish domain in varying contexts is another linguistic parameter.

Still, the data on OS languages is potentially even more disturbing to the LLP. If every single OS language that does not incorporate object anaphors into the $\mathrm{V}$ makes use of $\mathrm{c}$-command rather than linear precedence in defining domains even in local contexts, we would want to motivate an account of this fact. Since I have examined data on only four OS languages and since only one of these four does not make use of incorporation, I cannot pursue this question in detail here. However, I will make a tentative suggestion.

First, in languages in which the order of the object and subject is relatively free, as in Japanese, a variety of factors come into play in establishing potential binding relationships. For example, in Japanese, subjects that bear any theta role can bind zibun 'self', but only those nonsubjects that are experiencers can bind zibun (Sells 1987; Ue 1982). In Japanese, subjects are identifiable largely by particles (which have many similarities to case markers; see Shibatani 1989). Thus the binding of zibun makes use of information about grammatical functions and about thematic roles, as well as information about structure (c-command is required).

Now notice that in OS languages (like Malagasy) and in languages in which the subject and object fairly freely alternate in order (like Japanese), the linear order of the arguments of the verb does not correspond in a 
one-to-one fashion to the order of prominence of the arguments - so long as we admit that subjects are somehow more prominent arguments than objects. (And in Japanese, there are at least four grammatical phenomena that only subjects can participate in; see Shibatani [1989].)

I suggest that when the correspondence between linear order and grammatical prominence of arguments is not one-to-one, languages will employ factors other than linear prominence when establishing binding domains where the two relevant nodes are paesani. This is because the most comfortable fit is to have the binder be more grammatically prominent than the bindee with respect to the theta assigner that heads the XP that both are citizens of. If we take as a given that all languages can employ either linear prominence or c-command or both (and additional factors - as in Japanese), then it follows that one very likely factor that an OS language will adopt in binding (whether among paesani or not) is c-command.

Recall that there is considerable evidence that c-command is a crucial factor in establishing binding domains when the binder and the bindee are not local to one another even in English (see the discussion at the opening of section 4). One possible reason for this might be that as the structural relationship between the two relevant nodes becomes more complex, structure assumes more importance. This fact may tie in to the facts on OS languages and on languages such as Japanese. That is, when the linear order of two nodes does not parallel the relative grammatical prominence of those nodes with respect to a single theta assigner (either because subjects follow objects or because the two nodes are not citizens of the same phrase), binding between those two nodes is, in a sense, a more complex operation - and it must be based, accordingly, on more complex relationships. In such instances, c-command comes into play.

Regardless of whether the above discussion is on the right track, it looks likely that the LLP is not a universal principle of grammar. Nevertheless, none of the evidence in this section in any way undermines the clear evidence and arguments we found in sections 2 and 3 for the existence of the LLP in English.

\section{The double-object construction and domains}

The data on the double-object construction in section 2 can be accounted for with the LLP regardless of the hierarchical relationship of the two NPs to one another. Larson (1988), however, argues for an analysis of the double-object construction in which the first object asymmetrically c-commands the second. We will look at his analysis in section 7 immedi- ately below. The important point here is that if the first object asymmetrically c-commands the second, the domain facts in double-object constructions seen in section 2 follow with the traditional GB definition of domain based on c-command. However, since we have already seen in sections 2 and 3 that linearity is relevant to domain (as with the examples involving two PPs in [14]-[28]), the facts in section 2 cannot be taken as evidence for Larson's analysis of the double-object construction (although they are certainly consistent with his analysis).

Ideally, one would like to find data involving the double-object construction for which only one definition of domain would be adequate. Unfortunately, no such data exist so far as I know. Thus the viability of Larson's analysis should be judged with regard to how well it fares in accounting for other matters that do not involve questions of domain.

Larson's analysis has been given much credence - and one major reason is that many linguists insist on the binary-branching hypothesis. With the LLP, instead, a ternary-branching structure as well as various possible binary-branching structures are possible for the double-object construction, including those in (5b) and (42);

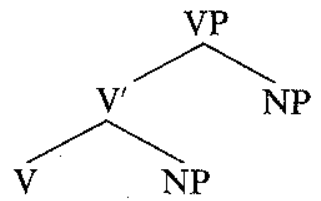

The very fact that the LLP allows for a ternary-branching analysis of the double-object construction might be taken by some as evidence against it. However, Carrier and Randall (1992) argue that ternary branching is needed to account for VPs that contain resultatives. Thus the fact that the LLP allows for ternary-branching structures should not be counted as evidence against its validity a priori.

I will now turn to other matters that allow us to judge the viability of Larsons' analysis.

\section{Larson's analysis of the double-object construction}

The initial motivation for Larson's analysis of the double-object construction (to account for facts involving domain relationships) has been removed. In addition, Jackendoff (1990) has raised serious problems for Larson's account, some of which Larson (1990) has successfully refuted. In Larson's refutations, he concedes that both a linear-precedence and a c-command-based definition of domain could handle the relevant data in 
all cases with the exception of two: he offers data and analysis of VP ellipsis and gapping constructions that are problematic for a linearprecedence definition of domain. Since both of these problematic cases involve a relationship between nodes that are not paesani, I will not go into them in this paper.

Instead, in this section I offer additional problems for Larsons's analysis.

\subsection{A precis of the analysis}

In order to understand the criticisms that follow, one needs an overview of Larson's intricate analysis. Larson offers a new analysis not just for double-object sentences, but for all sentences involving both a DO and an IO. He gives the VP in (43) the derivation shown in (44):

(43) John sent a letter to Mary.

(44) a.
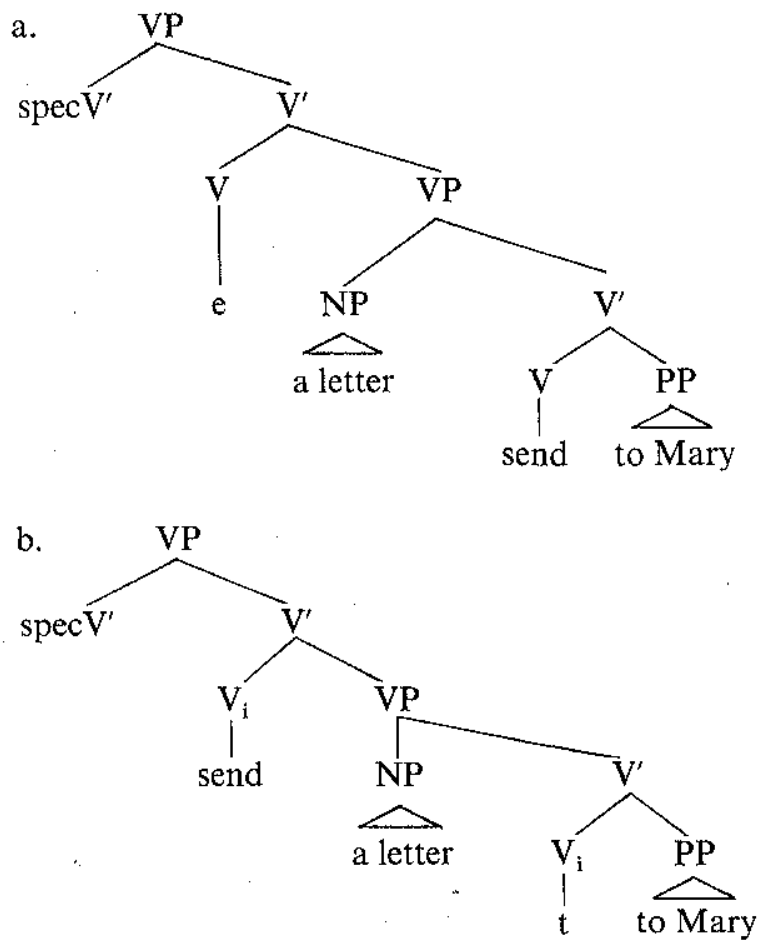

And Larson's analysis of the VP in (45) will have the derivation shown in (46).

(45) John sent Mary a letter.

(46) a.

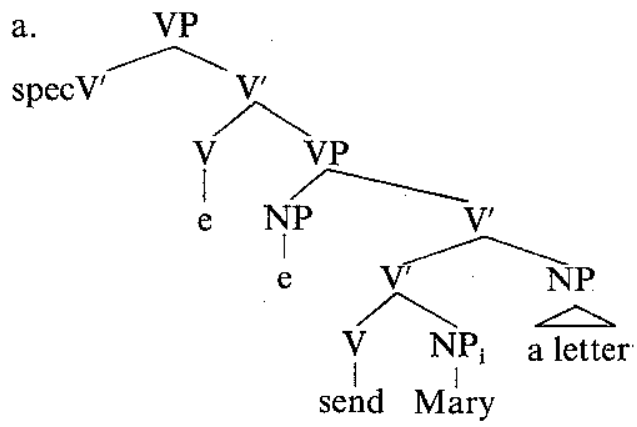

NP movement (dative
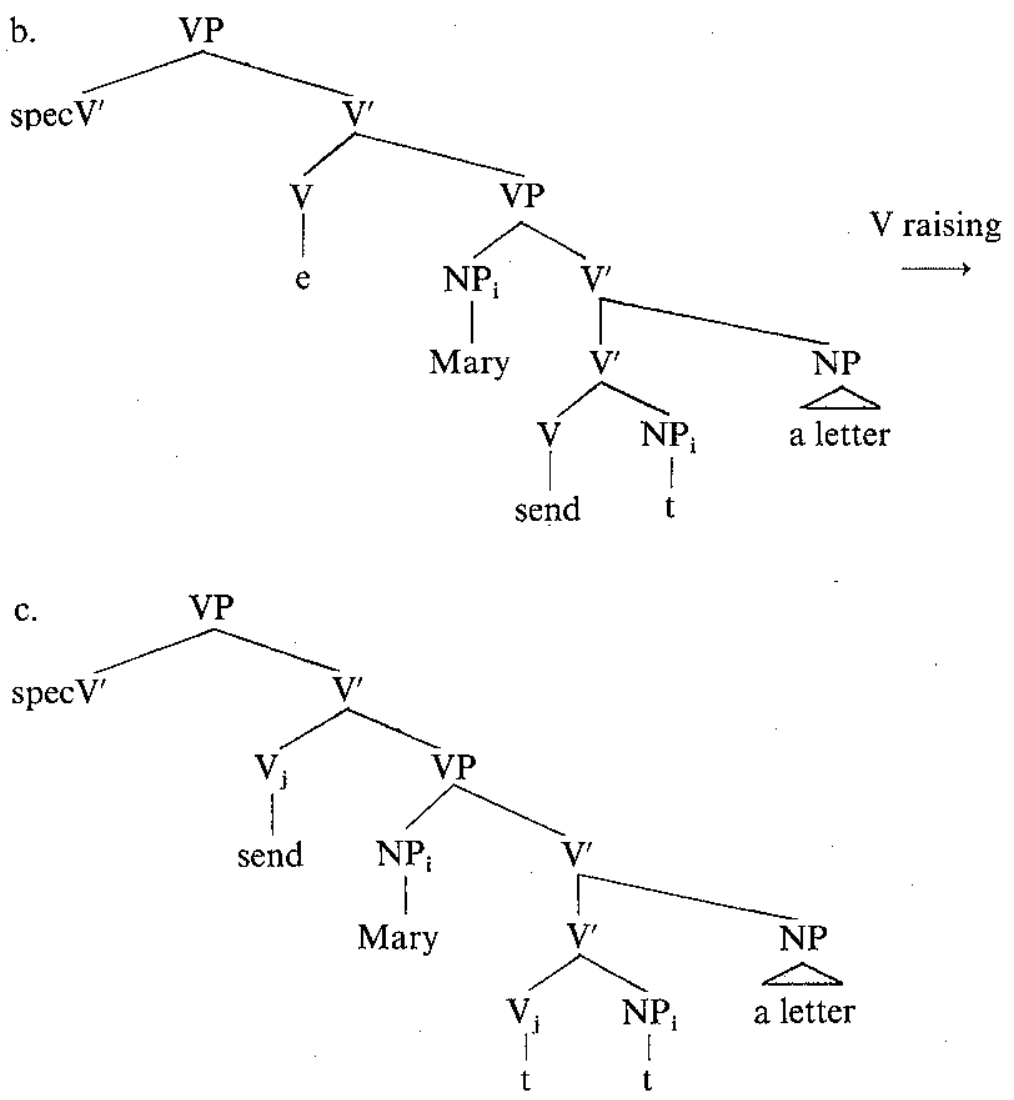
(There is no necessary ordering of NP movement and V-raising.) At $\mathrm{S}$ structure with Larson's analysis of the double-object construction (as in [46c]), we find that the first object asymmetrically c-commands the second object.

\subsection{Theta assignment in sentences with a metaphorical and a literal} reading

Larson claims that "the exact semantic role assigned to the direct object ... depends on the nature of the recipient appearing in the goal phrase" (1990: 340). Therefore the V plus the IO together assign a theta role to the DO. It then follows that the V plus the IO form a syntactic constitutent - the lowest. $V^{\prime}$ in (44a) and (46a). The examples Larson uses to exemplify this argument are the following:

(47) Beethoven gave the Fifth Symphony to the world.

(48) Beethoven gave the Fifth Symphony to his patron.

He says, "In the first case, we understand the given object to be the Fifth Symphony qua composition; the transfer of possession is metaphorical ... In the second case we understand a physical object to be transferred perhaps a sheaf of papers on which the composition is transcribed" (1990: 340).

One could quibble with Larson's characterization of the semantics of (47)-(48), but his point that a literal and a metaphorical reading are both possible and that the choice of the 10 affects our favored reading seems true. His conclusion, however, is incorrect.

First, why should the metaphorical/literal contrast get spelled out as a difference in theta roles for the DO? What would those different theta roles be? I cannot discern any difference in the theta roles of the DOs in (47)-(48) and Larson does not explicitly state what the differing theta roles would be.

Second, we find the same metaphorical/literal contrast in (49) and (50):

(49) I gave my life to Unicef.

(50) I gave $\$ 10$ to Unicef.

But here it is the choice of the DO that affects our favored or first readings. Given Larson's explanation of $(47)-(48)$, he would be led to claiming that the V plus DO form a constituent in (49)-(50), thus contradicting his own analysis of these constructions.

\subsection{Idioms and theta assignment}

Emonds (1972) points out idioms consisting of a V and its IO. Larson uses such idioms to argue that in sentences like (51) the DO receives its theta role from the combination of the $\mathrm{V}$ plus the $\mathrm{IO}-$ and since he is assuming that only a syntactic constituent can be a theta assigner, he presents such sentences as evidence for his claim that the $\mathrm{V}$ plus the IO form a constituent at $D$ structure.

(51) Felix threw Oscar to the wolves.

This argument is problematic. There are idiomatic frames that are not syntactic constituents in any phrase-structure-based theory but that assign a theta role to some NP, as, for example, in (52):

(52) The cat's got $[\ldots]_{\mathrm{NP}}$ 's tongue.

Therefore, the thematic structure of (51) does not offer evidence in support of the syntactic analysis Larson would assign it. (And we now see that the foundation upon which Larson bases his argument described in subsection 7.2 above is faulty.)

\subsection{Case assignment}

Larson argues that in (46c), repeated here, the NP a letter receives case from the circled $V^{\prime}$.

(46) $\mathrm{c}$

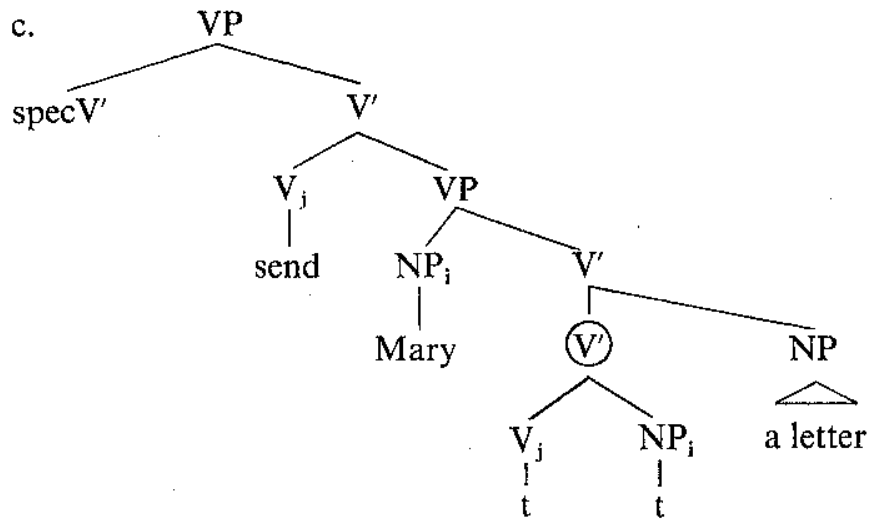

Here $\mathrm{V}_{\mathrm{j}}$ and $\mathrm{NP}_{\mathrm{i}}$ get reanalyzed into a new node (the circled $\mathrm{V}^{\prime}$ ), which is a case assigner. But if this were what generally happens in putative reanalysis cases, we would expect to be able to find other constructions besides the double-object construction in which an NP argument with no 
preposition preceding it could be found following reanalyzed verbs that consist of a V plus an NP. That is, regardless of any idiosyncratic semantic or lexical restrictions there may be on a given reanalysis rule (and the particular reanalysis rule Larson proposes has a series of idiosyncratic restrictions on it, such as that the oblique argument must be benefactive and only certain verbs are eligible), every putative reanalysis rule forming a V from a V-plus-NP should yield a V that has the same range of syntactic possibilities (given that the outputs of the putative rules are identical: V dominating V and NP). So if Larson's reanalysis rule can produce a new $\mathrm{V}$ that can assign case, then we might expect at least some other newly formed Vs to be case assigners, as well.

However, no such examples arise. Instead, in those instances in which one might propose reanalysis, forming a new $\mathrm{V}$ from a V-plus-NP combination, a preposition always appears to introduce a following NP:

(53) We took \{care/advantage ${ }^{*}$ (of) Jill.

(compare Jill was taken \{care/advantage of.)

The $\mathrm{P}$ which appears in (53), of, is precisely the $\mathrm{P}$ called for when no other case assigner is available (Anderson 1979). So if the V-NP combination take care/advantage is reanalyzed as a new $\mathrm{V}$, that new $\mathrm{V}$ is not a case assigner.

\subsection{P stranding}

Larson follows Kayne $(1981,1984)$ in saying that a $\mathrm{P}$ can be stranded only if it assigns objective case. He uses this proposal to account for the possibility of the double-object construction in English but not in Romance. In English since tolfor assigns objective case, their omission in the double-object construction is not a problem since the verb will assign the 10 the necessary objective case. But in Romance the counterparts to tolfor assign dative case, so they cannot be omitted.

Larson concludes that only $\mathbf{P}$-stranding languages can have the doubleobject construction.

The facts go against Larson's conclusion. The double-object construction and $\mathrm{P}$ stranding are free in the Scandinavian languages and in English. However, in German and Dutch the data are different.

In German we find the double-object construction, but $\mathrm{P}$ stranding is not allowed:

(54) Ich gebe dem Mann ein Buch.

'I give the man a book.'
(55) Du kommst nach ihm.

'You come after him.'

Nach wem kommst du?

after whom come you

'After whom do you come?'

*Wem kommst du nach?

whom come you after

'Who(m) do you come after?'

There is only one instance that has been pointed out to me (by Jack Hoeksema, personal communication 1989) of a case of what looks like $P$ stranding in German, and that is a marginally grammatical one at best in most varieties of German, although more common in Low German (including the Berlin dialect, as in Zuckmayer 1930).

(56) ? Da habe ich nicht von verstanden. there have I not of understood

'I have not understood about it:'

Here $d a$ is a locative meaning 'there', and it is understood as the object of the $\mathrm{P}$ von.

Larson also mentions Dutch as having the double-object construction. But Dutch does not freely allow P stranding. Van Riemsdijk (1978) argues at length that there are only three instances in which Ps can be stranded in Dutch. (1) A certain class of pronouns (called R pronouns) can front out of PP, but no other NPs or pronouns can. (2) Locatives (including the clitic er) can front out of PPs (similarly to our where, but not our $w h a t$ ), in a way comparable to the German sentence with $d a$ in (45). (3) In some nonstandard varieties of Dutch, P stranding is free. However, the double-object construction in Dutch is not restricted to just R pronouns, locatives, or nonstandard varieties of speech. It is as productive a construction as its English counterpart.

Furthermore, Chinese has double-object constructions (with IO-DO order in Mandarin and DO-IO order in Cantonese; see Norman 1988), but no P stranding (Zhang 1988, 1990), as does Indonesian (Muadz 1988, cited in Zhang 1990).

There is no obvious correlation between the ability to P-strand and the ability to exhibit the double-object construction in a given language.

\section{Conclusion}

Linearity is the only syntactic factor relevant to determining a domain relationship between paesani. In fact, linearity is the only syntactic factor 
relevant to determining domain relationships between other nodes that are local to one another, but $I$ have been unable to come up with an adequate revision of the notion of paesano to cover these additional cases. We have come to this conclusion by examining instances of asymmetric binding possibilities with nodes that either mutually c-command one another or mutually do not c-command one another.

Furthermore, the evidence here suggests that Larson's analysis of the double-object construction is incorrect. In particular, there is no evidence that the first object asymmetrically c-commands the second or that the $\mathrm{V}$ and the IO form a theta-assigning syntactic constituent. Additionally, Larson's analysis meets serious problems regarding case assignment and incorrectly predicts a correlation between the ability to P-strand and the ability to exhibit the double-object construction in a given language. In contrast, certain alternative analyses of the double-object construction do not meet these problems. Let me end with the simple observation that a ternary-branching structure for the double-object construction in which both NPs are sisters to the $\mathrm{V}$ is consistent with all of the data presented here.

Received 4 March 1991

Revised version received

15 June 1992

\section{Notes}

* For discussions about German data, I thank Marion Faber and Barbara Schmidt. For discussions about Dutch and German data, I thank Jack Hoeksema. For discussions about Japanese data, I thank Kaori Kitao and Mutsuko Hudson. For discussions about Tzotzil data, I thank Judith Aissen. For discussions about OS languages, I thank Virginia Brennan and Larry Solan. And for comments on an earlier version of this paper, I thank Michael Bernstein, Jack Hoeksema, Eric Hoekstra, Beth Levin, Anne Zribi-Hertz, Barry Miller, and Shi Zhang, as well as the anonymous reviewers. Correspondence address: Department of Linguistics, Swarthmore College, Swarthmore, PA 19081, USA.

1. Richardson and Chametzky (1985) point out problems with formalization of this definition of c-command, which is due to Reinhart $(1976,1979)$.

2. Sometimes one of the orders results in ungrammaticality, as in (i):

(i) *I talked about Jim to himself.

an effect that Postal (1971) attributed to a violation of his crossover principle, which essentially blocks movement of a referential item across another item that it is corefer. ential with. Jackendoff (1972) offers another account, attributing the ungrammaticality of examples like (i) to a violation of his thematic hierarchy condition on reflexives, which states, "A reflexive may not be higher on the Thematic Hierarchy than its antecedent" (1972: 148). The TH is

Agent

Location, Source, Goal

Theme.

While such examples are problematic for the definition of domain based on linear precedence that $I$ will present in section 4 in that they call for a complex explanation such as that of Postal or Jackendoff, they are equally problematic for a definition of domain based solely on c-command in that they call for a complex explanation that will distinguish between the two PPs structurally. For example, Larson (1990) claims that in an example such as

(ii) *I talked about Jim to himself.

Jim does not c-command himself. But in an example such as

(iii) I talked to Jim about himself.

Jim does c-command himself. That is, the preposition about in (ii) blocks c-command by its object of material outside the PP, but the preposition to in (iii) does not.

In section 3 below I discuss questions of c-command and prepositions. There I argue against c-command distinctions between examples like (ii) and (iii). Thus the distinction between (ii) and (iii) is problematic regardless of one's definition of domain.

3. The examples in (8) and (9) are all instances of weak crossover in a theory in which the relevant domain relationships are established at LF after quantifier raising of the quantified NP. The ungrammaticality of the second example of each pair in both (8) and (9) would be attributed to a violation of the bijection principle, by which any operator binds precisely one variable and every variable is bound by a single operator. For example, consider $(9 \mathrm{a})$, repeated here:

(i) [Which trainer $]_{\mathrm{i}}$ did you show $[\mathrm{t}]_{\mathrm{j}}\left[[\text { his }]_{\mathrm{i}}\right.$ lion $]$ ?

(ii) $*[\text { Which lion }]_{i}$ did you show $\left[[i t s]_{i}\right.$ trainer $[t]_{i}$ ?

In (i) which trainer binds trace, which in turn binds his. But in (ii) which lion must be taken to bind both trace and its, since this trace is a variable so it must be coindexed with an operator and since this trace cannot bind its because it doesn't have domain over its. But, then, (ii) is a violation of the bijection principle.

Notice that this account of (i)-(ii) holds whether one's definition of binding domain is based on c-command or on linear precedence. That is, the trace in (ii) neither c.commands nor precedes its.

Although (8) and (9) are examples of a single phenomenon in GB, I list examples with quantified-NP-bound pronouns separately from examples with WH movement and weak crossover in this paper, following the model established in Barss and Lasnik and continued in Larson and Jackendoff.

4. As Barss and Lasnik point out, the superiority condition is controversial. Many data originally taken to support this condition are now accounted for by some version of the empty-category principle (Chomsky 1981; Lasnik and Saito 1984). Still, some argue that the superiority condition is needed (Pesetsky 1982; Hendrick and Rochemont 1982), if in a modified form.

5. That polarity any is licensed only in the domain of scope-bearing elements is argued in Klima (1964), Lasnik (1975), Horn (1972), Kroch (1974), Ladusaw (1979), and Linebarger (1980). 
6. Even Baker (1988), who allows reanaiysis to operate on a string with an NP intervenor, disallows reanalysis on a string with a temporal or other adverbial intervenor.

7. While Hornstein and Weinberg argue that both WH movement and passivization are diagnostics for reanalysis, other have shown that preposition stranding in the two types of construction obey different sorts of constraints (Chomsky 1985: 201-202).

8. The first pair in (17), that involving binding of a reflexive, involves coordination. A referee of this article offered me a similar pair. However, besides examples involving coordination, most examples I have constructed sound at best marginal to my ear when the antecedent precedes the anaphor.

(i) ??I gave snapshots to [John] for [himself $]_{i}$.

Perhaps the sense of (i) is the source of the problem. That is, in (17) one party is giving snapshots to a second party for a third party. But in (i) the second and third parties are the same person, so a bizarre situation is created in which John is to pass on the snapshots to himself. Alternatively, some other factor that I cannot guess at is at play here. In either case, (ii), in which the anaphor precedes the antecedent, is much worse:

(ii) *I gave the snapshots to [himself $]_{i}$ for $[\text { John }]_{\text {i }}$.

Given the ungrammaticality of (ii) and the first pair in (17) in the text, I presume that the proper explanation for (i) will not bear crucially on the disucssion in the text.

9. Larson $(1988,1990)$ proposes a reanalysis operation by which any predicate projection that is thematically monotransitive may be reanalyzed as a V. However, even in his analysis the string gave snapshots ( $t o$ ) would not form a (newly reanalyzed) V at any point in the derivation of the sentences in (17).

10. Some speakers I have asked who accept (18)-(20) reject other sentences with similar structure, such as (i) (suggested to me by an anonymous referee):

(i) *The phantom of the opera stood behing each soprano $o_{i}$ on her $r_{i}$ debut.

Although I do not know what factors influence the judgment here, the structure (both syntactic and thematic, as discussed immediately below in the text) of (i) is identical in all relevant respects to the structure of $(18)$ in the text. Thus for the many speakers who accept other sentences with this structure, the point in the text holds.

I should point out, however, that binding of a reflexive is generally disallowed in these contexts for all speakers I have asked:

(ii) ${ }^{*}$ I spoke after $J \mathrm{hhn}_{\mathrm{f}}$ about himself

*I spoke about John after himself $\mathrm{f}_{\mathrm{i}}$

I have argued elsewhere (Napoli 1989: chapter 6) that with the exception of emphatic reflexives, both reflexives and their antecedents occur in argument positions, thus accounting for the ungrammaticality of (ii)

Note that examples such as

(iii) I like John's picture of himself

at first seem to be counterexamples to this claim. However, Napoii (1989:45) argues that the so-called picture nouns evoke an event structure, so that both John's and himself do, in fact, behave like arguments of the noun picture in (iii).

11. This definition of citizen is similar to the definition of member of an argument rung (on the argument ladder) in Napoli (1989). But members of argument rungs do not include all adjuncts, whereas all adjuncts are citizens of some phrase. Thus the term citizen is more inclusive.
12. Polarity any can be licensed by a possessive in sentences parallel to those in (31): (i) I swear to you: I offered no one's sister to anyone?

However, the other domain relationships exemplified in section 2 above do not allow possessives to have domain over items outside the NP that the possessive is contained within.

13. Not just VPs, but any phrase whose head is a theta assigner can have citizens. Thus single-clause sentences that contain, for example, nouns that are theta assigners (such as picture nouns and many other types; see Anderson 1983) involve more than one set of citizens. Examples used to show the relevance of c-command to binding of anaphors that use single-clause sentences with multiple theta assigners (as in Mohanan 1983 and the sources cited there), then, are not covered by (30) unless the binder and the bindee are paesani.

14. Sentences with preposed phrases offer a further testing ground for whether or not the definition in (29) is too inclusive. However, while Reinhart (1981) offered such examples (and some of them involve binding between paesani) to argue that c-command was a relevant factor for binding, the situation is not so straightforward as Reinhart initially thought. Others have shown that such cases often involve reconstruction, so that the binding possibilities are sometimes calculated not from position at $\mathrm{S}$ structure, but from position at D structure (Cinque 1982; Barss 1986; Lebeaux 1988). A study of examples involving preposing as a test for the definition in (29) is called for (and is taken up in future research).

15. Jackendoff (1990: 453) offers a contrast in binding possibilities that he attributes to syntactic configuration:

(i) I sent John and Bil to each other's classrooms.

(ii) ?*I saw John and Bill during each other's classes.

If the two PPs are attached at different points (the $t o$ as a sister to the conjoined NP and the during at a higher point), then the c-command condition on binding can be appealed to here to account for the difference in grammaticality. It was this sort of concern that led Jackendoff to propose that both c-command and linear precedence are important to determining domain.

Since the two relevant NPs in (i) and (ii) are not paesani (given that the possessive is not a citizen of the VP), my proposal in (30) has nothing to say with respect to the ungrammaticality of (ii). Nevertheless, I suspect that contrasts like the one between (i) and (ii) should not be accounted for with a c-command restriction on the domain of binding here. The contrast found in (i)-(ii) is not duplicated for the other phenomena discussed in Barss and Lasnik:

(iii) I sent each boy ${ }_{\mathrm{i}}$ to his, ${ }_{1}$ classroom.

I saw each boy during his $_{\mathrm{i}}$ first class.

(iv) Who $\mathrm{O}_{\mathrm{i}}$ did you send to his $\mathrm{s}_{\mathrm{i}}$ room?

Who, did you see during his, class?

(v) Who did you send to which classroom?

Who did you see during which lesson?

(vi) I sent each boy $y_{i}$ to the other' $s_{i}$ classroom.

I saw each boy, during the other's $s_{i}$ lesson.

(vii) I sent no boy to any classroom.

I saw no boy during any lesson.

(The reverse order of the relevant nodes in [iii]-[vii] results in ungrammaticality, as the reader can easily test (for example, ${ }^{*} I$ sent him to $_{\mathrm{i}}$ each boy's $s_{\mathrm{i}}$ classroom).) 
The contrast in grammaticality between (i) and (ii), then, is probably not due to structural factors on the determination of domains. While I know of no treatment of this difference in the literature, it is well known that reciprocals display certain peculiarities that are not shared by reflexives (typically instances in which a reciprocal is grammatical in a position from which a reflexive is rejected). This fact, however, need not constitute evidence that whatever binding conditions are violated here should be reformulated. Instead, as Lebeaux (1983) shows, sometimes those differences should be attributed to autonomous principles in the grammar (where Lebeaux argues that the distributive nature of the interpretation of reciprocals is the source of the difference). And, in fact, there is evidence that the binding of reciprocals is not as sensitive to linearity as the binding of reflexives is:

(viii) ${ }^{*}$ I confronted with himself $f_{1}[\text { the most violent patient } I \text { had }]_{\text {i. }}$.

(ix) ??I confronted with each other's problems [two patients who were particularly hopeless cases].

(ix) was pointed out to me by Eric Hoekstra (personal communication, 1989), who reported it as grammatical. The double question mark reflects my own grammaticality judgment here.

Lebeaux's examples differ from the sort of data we see in (i)-(ii) in that the contrast is between refiexives and reciprocals (as in [viii]-[ix]), not between two sentences both involving reciprocals. Still, I suggest that a study of the semantics of the prepositions 10 and during in light of the semantics of reciprocals might be a place to start in trying to account for the contrast in (i)-(ii).

16. I will not discuss further here this notion of locality since I have argued elsewhere that the notion of "accessible subject" on which it is based is incoherent (Hoeksema and Napoli 1990). Instead, I will appeal to the reader's knowledge of the usual array of data that are taken to show locality effects, such as

(i) Bill ${ }_{i}$ loves photos of himself

*Billi loves Jill's photos of himself

(ii) Bill loves himself $f_{i}$.

${ }^{*} B_{i l l}$ said Mary loves himself

17. As evidence that the possessive in (34) does not bear a theta role, but that in (35) does, consider anaphoric epithets. These epithets, like other $R$ expressions, cannot be A-bound (Lasnik 1976)

(i) *The baby $y_{i}$ babbled to the little darling.

As predicted, these epithets can be coindexed with a non-theta-bearing possessive but not with a theta-bearing possessive:

(ii) I handed the baby's $s_{i}$ mother the little darling $\mathrm{s}_{\mathrm{i}}$

(iii) *I cursed the Huns', destruction (of the city) to the bastards

(compare I cursed the Huns' destruction (of the city) to myself.)

18. Other speakers feel uncomfortable with (39) and offer (i) instead:

(i) Ho parlato a Maria ${ }_{i}$ di lei stessa $a_{\text {. }}$.

'I spoke with Maria about herself.'

In (i) instead of the anaphor se (stessa), we find the special pronoun lei stessa, which has interesting and different properties from the ordinary pronoun lei. We will not go into those properties here since they do not shed light on the issue in the text.

\section{References}

Anderson, Mona (1979). Noun phrase structure. Unpublished Ph.D. dissertation, University of Connecticut.

- (1983). Prenominal genitive NPs. Linguistic Review 3, 1-24.

Bach, Emmon; and Partec, Barbara (1980). Anaphora and semantic structure. In Papers from the Parasession on Pronouns and Anaphora, J. Kreiman and A. Ojeda (eds.), 1-28. Chicago: Chicago Linguistic Society.

Baker, Mark (1988). Incorporation: A Theory of Grammatical Function Changing. Chicago: Chicago University Press.

Barss, Andrew (1986). Chains and anaphoric dependence: on reconstruction and its implications. Unpublished Ph.D. dissertation, MIT.

—; and Lasnik, Howard (1986). A note on anaphora and double objects. Linguistic Inquiry $17,347-354$.

Burzio, Luigi (1986). Italian Syntax. Dordrecht: Reidel.

Carrier, Jill; and Randall, Janet (1992). The argument structure and syntactic structure of resultatives. Linguistic Inquiry 23, 173-234.

Chomsky, Noam (1981). Lectures on Government and Binding. Dordrecht: Foris.

-(1985). Knowledge of Language. New York: Praeger.

-(1986). Barriers. Cambridge, MA: MIT Press.

Chung, Sandra; and McCloskey, James (1987). Government, barriers and small clauses in Modern Irish. Linguistic Inquiry 18, 173-237.

Cinque, Guglielmo (1982). Island effects, subjacency, ECP/connectedness and reconstruction. Unpublished manuscript, Università di Venezia.

Colarusso, John (1976). An instance of unbounded rightward movement: $W h$-movement in Circassian. Unpublished manuscript; University of Vienna.

Cowart, Wayne (1990). Interpreting reflexives in coordinate NPs: evidence for a nonsyntactic analysis of NP coordination. Unpublished manuscript, University of Southern Maine.

Derbyshire, Desmond (1977). Word order universals and the existence of OVS languages. Linguistic Inquiry 8, 590-599.

-(1979a). Hixkaryana. Lingua Descriptive Studies 1. Amsterdam: North-Holland.

- $(1979$ b). Hixkaryana syntax. Unpublished doctoral dissertation, University of London.

Emonds, Joseph (1972). Evidence that indirect object movement is a structure-preserving rule. Foundations of Language 8, 546-561.

Giorgi, Alessandra (1984). Toward a theory of long distance anaphors. Linguistic Review 3 , $307-361$.

-(1987). The notion of complete functional complex: some evidence from Italian. Linguistic Inquiry $18,511-518$.

-; and Longobardi, Giuseppe (1991). The Syntax of Noun Phrases. Cambridge: Cambridge University Press.

Grimshaw, Jane (1988). Adjuncts and Argument Structure. Lexicon Project Working Paper 21, Occasional Paper 36. Cambridge, MA: Center for Cognitive Science, MIT.

Hendrick Randall; and Rochemont, Michael (1982). Complementation, multiple WH, and echo questions. Unpublished manuscript, University of North Carolina and University of California at Irvine.

Hoeksema, Jack; and Napoli, Donna Jo (1990). A condition on circular chains: a restatement of i-within-i. Journal of Linguistics $26,403-424$

Horn, Lawrence (1972). On the semantic properties of logical operators in English. Unpublished Ph.D. dissertation, UCLA. 
Hornstein, Norbert (1984). Logic as Grammar: An Approach to Meaning in Natural Language. Cambridge, MA: MIT Press.

-; and Weinberg, Amy (1981). Case theory and preposition stranding. Linguistic Inquiry $12,55-92$.

Jackendoff, Ray (1972). Semantic Interpretation in Generative Grammar. Cambridge, MA: MIT Press.

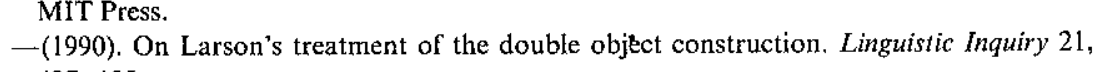
$427-455$.

Kajita, Masaru (1977). Towards a dynamic model of syntax. Studies in English Linguistics $5,44-76$.

Kayne, Richard (1981). On certain differences between French and English. Linguistic Inquiry 12, 349-371.

-(1984). Datives in French and English. In Connectedness and Binary Branching, 193-202. Dordrecht: Foris.

Keenan, Ed (1976). Remarkable subjects in Malagasy. In Subject and Topic, Charles Li (ed.), 247-301. New York: Academic Press.

Klima, Edward (1964). Negation in English. In The Structure of Language: Readings in the Philosophy of Language, J. Fodor and J. Katz (eds.), 246-323. Englewood Cliffs, NJ: Prentice-Hall.

Kroch, Anthony (1974). The semantics of scope in English. Unpublished Ph.D. dissertation, MIT.

Ladusaw, William (1979). Polarity Sensitivity as Inherent Scope Relations. New York: Garland.

Langacker, Ronald (1966). On pronominalization and the chain of command. In Modern Studies in Engtish, D. Reibel and S. Schane (eds.), 160-186. Englewood Cliffs, NJ: Prentice-Hall.

Larson, Richard (1988). On the double object construction. Linguistic Inquiry 19, 335-391. -(1990). Double objects revisited: reply to Jackendoff. Linguistic Inquiry 21, 589-632.

Lasnik, Howard (1975). On the semantics of negation. In Contemporary Research in Philosophical Logic and Linguistic Semantics, D. Hockney, W. Harper, and B. Freed (eds.), 279-311. Dordrecht: Reidel.

-(1976). Remarks on coreference. Linguistic Analysis 2, 1-22.

-(1989). Essay's on Anaphora. Dordrecht: Kluwer.

-; and Saito, Mamoru (1984). On the nature of proper government. Linguistic Inquiry 15, $235-289$.

Lebeaux, David (1983). A distributional difference between reciprocals and reflexives. Linguistic Inquiry 14, 723-730.

-(1988). Language acquisition and the form of the grammar. Unpublished Ph.D. dissertation, University of Massachusetts at Amherst.

Lee, Thomas Hun-tak (1991). Linearity as a scope principle for Chinese: the evidence from first language acquisition. In Bridges Between Psychology and Lingusitics: A Swarthmore Festschrift for Lila Gleitman, D. J. Napoli and J. Kegl (eds.), 183-206. Hillsdale, NJ: Erlbaum.

Linebarger, Marcia (1980). The grammar of negative polarity. Unpublished Ph.D. dissertation, MIT.

May, Robert (1985). Logical Form: Its Structure and Derivation, Cambridge, MA; MIT Press.

Mohanan, K. P. (1983). Functional and anaphoric control. Linguistic Inquiry 14, 641-674.

Muadz, H. (1988). Double object construction as a lexical rule: evidence from Indonesian. Unpublished manuscript, University of Tucson, Arizona.
Napoli, Donna Jo (1989). Predication Theory: A Case Study for Indexing Theory. Cambridge: Cambridge University Press.

Norman, Jerry (1988). Chinese. Cambridge: Cambridge University Press.

Pesetsky, David (1982). Paths and categories. Unpublished Ph.D. dissertation, MIT.

Postal, Paul (1971). Cross-Over Phenomena. New York: Hoit, Rinehart and Winston.

Pullum, Geoffrey (1980). Languages in which movement does not parallel bound anaphora. Linguistic Inquiry 11, 613-620.

Reinhart, Tanya (1976). The syntactic domain of anaphora. Unpublished Ph.D. dissertation, MIT.

-(1979). Syntactic domains for semantic rules. In Formal Semantics and Pragmatics for Natural Language, F. Guenthner and S. Schmidt (eds.). Dordrecht: Reidel.

-(1981). Definite NP anaphora and c-command. Linguistic Inquiry 12, 605-636.

-(1987). Specifier and operator binding. In The Representation of (In)definiteness, E. Reuland and A. ter Meulen (eds.), 130-167. Cambridge, MA: MIT Press.

Richardson, J.; and Chametzky, Robert (1985). A string based reformulation of c-command. NELS 15, 332-361.

Ruszkiewicz, Piotor (1984). Topics in the Grammar of English Reflexives. Bloomington: Indiana University Linguistics Club.

Sells, Peter (1987). Aspects of logophoricity. Linguistic Inquiry 18, 445-479.

Shibatani, Masayoshi (1989). The Languages of Japan. Cambridge: Cambridge University Press.

Ue, Noriko (1982). A crossing constraint in Japanese syntax. Unpublished doctoral dissertation, University of Michigan.

van Riemsdijk, Henk (1978). A Case Study in Syntactic Markedness: The Binding Nature of Prepositional Phrases. Dordrecht: Foris.

Williams, Edwin (1982). The NP cycle. Linguistic Inquiry 13, 277-295.

Zhang, Shi (1988). On the relationship between reanalysis and preposition stranding. Paper presented at the winter meeting of the LSA, New Orleans.

-(1990). Correlations between the double object construction and preposition stranding. Linguistic Inquiry 21, 312-316.

Zuckmayer, Carl (1930). Der Hauptmann von Kopenick. Berlin: Tropylaen Verlag. 